\title{
PARTICIPAÇÃO, DESENHO INSTITUCIONAL E ALCANCES DEMOCRÁTICOS: UMAANÁLISE DO CONSELHO DAS CIDADES (CONCIDADES)
}

\author{
Flávia de Paula \\ Duque Brasil
}

\author{
Ricardo Carneiro
}

\author{
Thiago Pinto \\ Barbosa
}

\author{
Mariana Eugenio \\ Almeida
}

\begin{abstract}
RESUMO
O artigo aborda a participação social em instituições participativas, com foco no Conselho das Cidades (ConCidades), criado em 2004 no âmbito federal. O trabalho objetiva analisar o desenho institucional do conselho, seus potenciais, limites e alcances, no que se refere aos avanços na construção das políticas urbanas no periodo 2004-2010. Colocase em questão se os elementos do desenho participativo do ConCidades favorecem ou não a realização dos potenciais de inclusão e de democratização das políticas urbanas. O desenvolvimento da pesquisa, realizada em 2010-2011, partiu de aportes no campo da democracia participativa, com ênfase nas instituições participativas, seus potenciais e elementos de variação. Destacando que a participação depende de fatores contextuais, de sua trajetória, do perfil da sociedade civil, do comprometimento do governo e dos desenhos institucionais, dirige-se a atenção para este último aspecto. O modelo analítico ancora-se em Fung (2004; 2006) e estrutura-se em três eixos: (i) participantes, (ii) formas de tomada de decisão e (iii) vinculação das decisões às políticas. A metodologia empregou recursos quali-quanti, realizando levantamentos documentais relativos ao Ministério das Cidades, às políticas urbanas no periodo e às Conferências das Cidades; neste último caso examinando e sistematizando as atas de suas reuniões e suas resoluções. A pesquisa indica o potencial democrático de o ConCidades engendrar avanços nas políticas urbanas e seus marcos legais, com variações ao longo da trajetória de sua atuação. Em relação ao desenho, salientase que a composição e a forma de escolha de representantes, dentre outros elementos, favorecem a inclusão politica e a participação. Evidenciam-se, também, limitações, principalmente seu caráter consultivo em relação às decisões da política, que tem sido objeto de questionamentos societários e propostas de alteração. Para além do desenho participativo, mudanças no âmbito institucional no Ministério e processos de participação na sociedade civil afetaram as práticas participativas e seus desdobramentos. Neste útimo sentido, destaca-se influência dos atores coletivos que integram o Fórum Nacional de Reforma Urbana, por meio de vários processos e repertórios de atuação. De uma perspectiva geral, o trabalho situa-se nos debates sobre as instituições participativas - particularmente conselhos -, enfatizando o desenho institucional como elemento que pode favorecer ou desfavorecer a participação deliberativa e seus efeitos nas políticas. De forma especifica, contribui ao focalizar uma experiência recente de participação nas politicas urbanas federais, ainda relativamente pouco abordada, passivel de aprimoramento.
\end{abstract}

PALAVRAS-CHAVE: democracia; participação social; desenho institucional participativo; ConCidades; política urbana.

\section{INTRODUÇÃO' ${ }^{1}$}

Os desenvolvimentos teóricos nas últimas décadas em torno da qualidade da democracia e do aprofundamento democrático têm se ampliado, seja sob a rubrica de democracia participativa (PATEMAN,

\footnotetext{
1 Pesquisa realizada com suporte financeiro da Fundação de Amparo à Pesquisa do Estado de Minas Gerais (Fapemig), por meio de Bolsas de Incentivo à Pesquisa concedidas aos dois primeiros autores e Bolsas de Iniciação aos demais, ao lado do financiamento do o Projeto Políticas Urbanas e Instituições Participativas. Agradecemos aos pareceristas anônimos da Revista de Sociologia e Política pelas sugestões feitas a este artigo.
}

1970; SANTOS \& AVRITZER, 2002; WARREN, 2002; FUNG \& WRIGHT, 2003; AVRITZER, 2009a), seja na trilha deliberativa que tem se mostrado fértil a partir de Habermas (HABERMAS, 1997; DRYZEK, 2000; COHEN \& FUNG, 2004; GUTMAN \& THOMPSON, 2007; CHAMBERS, 2009). No bojo desses debates, entre convergências e dissensos, destacam-se as possibilidades democratizantes complementares das formas de participação e de deliberação no terreno da sociedade civil e no âmbito de instâncias criadas para essa finalidade no Estado.

No caso brasileiro, desde o contexto de redemocratização do país na década de 1980, marcada por um ciclo de mobilizações, e notadamente após a 
promulgação da Constituição Federal de 1988 (CF-88) e da posterior legislação das políticas sociais, tem ocorrido a proliferação de canais de participação nas políticas públicas, resultando em um repertório amplo e heterogêneo quanto a seus desenhos, processos participativos e potenciais de fortalecimento ou aprofundamento democrático. Os canais de participação institucionalizados são referidos por Avritzer (2008, p. 3) como "instituições participativas", definidas como "formas diferenciadas de incorporação dos cidadãos e associações da sociedade civil nas deliberações públicas".

A expansão do número e tipo de instituições participativas pode ser associada a diversos fatores e antecedentes, desde as experiências pontuais precursoras de participação nos governos locais ainda no contexto autoritário e sua distensão com o experimentalismo nos governos locais de orientação democrático-popular no início da década de 1990, até a ampliação mais expressiva deste novo tecido participativo institucional nos anos seguintes.

No âmbito da sociedade civil, destaca-se a complexidade e pluralidade das formas de organização e mobilização, encampando movimentos sociais, associações e redes societárias nucleadas em torno de diversos motes, cujas bases, em muitos casos, são anteriores ao período de transição democrática (DOIMO, 1995; GOHN, 1995; SCHERER-WARREN, 1996; COSTA, 1997; TEIXEIRA, 2000; AVRITZER, 2009). Para além da densidade do tecido associativo, ressalta-se ainda a disposição dos atores organizados, a partir da década de 1980, de estabelecimento de interlocuções com o Estado e de engajamento em experiências de participação institucionalizada. Mais além, como observado por diversos autores (DAGNINO, 2002; SANTOS \& AVRITZER, 2002; FARIA, 2008), os atores organizados irrigaram a esfera pública com reivindicações e propostas de criação de instituições participativas, apostando nas possibilidades de sua incidência nos processos decisórios e nos potenciais desses novos arranjos. Os projetos societários incorporam-se notoriamente ao novo texto constitucional em seu viés descentralizante, democratizante e de ampliação dos direitos sociais e ganham corpo na legislação posterior das políticas sociais.

Assim, seja a partir de recomendações ou exigência da criação de instituições participativas, seja a partir da iniciativa dos governos e da propulsão da sociedade civil, o tecido participativo institucional no país compõese de conselhos de políticas ou temáticos, de conferências, orçamentos participativos, audiências públicas, arranjos participativos para a elaboração de planos, entre outros, que compartilham de elementos constitutivos como o caráter híbrido de interlocução entre Estado e sociedade, nos termos de Avritzer e Pereira (2005). A possibilidade de influência ou de intervenção dos atores sociais nas tomadas de decisão e a articulação, de diferentes modos, de mecanismos de participação, de deliberação e de representação são ampliadas para além dos mecanismos de representação eleitoral.

Entre os potenciais antevistos para esses canais de participação ampliada sublinham-se as possibilidades de aprendizagens democráticas e de construção de novas gramáticas relacionais entre Estado e sociedade. Outro potencial refere-se ao experimentalismo e às possíveis inovações no desenho, conteúdo e formas de gestão mais justas e legítimas de políticas públicas. Sublinham-se, também, os potenciais inclusivos das instituições participativas, considerando-se a confluência das desigualdades sociais com as assimetrias históricas de poder político entre os diversos grupos sociais e possibilidades de inclusão social. Ou seja, na medida em que essas instâncias ensejam a inclusão política de grupos tradicionalmente excluídos dos processos decisórios no âmbito do Estado, tem-se um horizonte possível de inclusão social. Esses potenciais imbricam-se na perspectiva de radicalização ou aprofundamento democrático, associada às práticas de participação, de deliberação $\mathrm{e}$ mesmo de representação no interior das instâncias participativas.

A expressão das experiências de participação institucionalizadas nas últimas décadas, sobretudo no caso dos conselhos de políticas, a diversidade de arranjos e as amplas variações nos seus alcances democráticos e de realização de seus potenciais justificam os esforços analíticos de sua abordagem, tendo em vista contribuir para o aprimoramento de tais práticas. Nesse sentido, os conselhos têm sido objeto recorrente de abordagem na literatura (SANTOS, 2002; TATAGIBA, 2002; GOHN, 2004; AVRITZER \& PEREIRA, 2005; CÔRTES, 2005; FARIA, 2008; LÜCHMANN, 2008; AVRITZER, 2009b; CUNHA et alii, 2011; PIRES, 2011).

O foco deste artigo recai sobre o ConCidades, criado em 2004, constituindo, portanto, um marco e uma experiência recente de participação nas políticas urbanas federais, ainda relativamente pouco abordada, destacando-se os trabalhos Santos Júnior (2007), Maricato e Santos Júnior (2007), Brasil (2011) e Rodrigues (2011). Tem-se, então, como objetivo, caracterizar e analisar seu desenho institucional participativo, seus potenciais, limites e alcances democráticos a partir do funcionamento da referida instância no período 2004-2010. Coloca-se em questão em que medida os elementos do desenho institucional 
do ConCidades afetam seu funcionamento e os desdobramentos de sua atuação nas políticas urbanas, tendo em vista o horizonte normativo associado às instituições participativas que remete aos potenciais de inclusão política e de democratização.

Para tanto, a metodologia adotada sustenta-se em recursos qualitativos, envolvendo inicialmente uma revisão bibliográfica sobre o tema e objeto de abordagem, tendo em vista, inclusive, o estabelecimento de parâmetros analíticos. Ao lado disso, desde 2010 efetuaram-se levantamentos documentais relativos ao Ministério das Cidades (MCidades), Conferências das Cidades, ao ConCidades e às políticas urbanas federais que têm sido formuladas no período e a seus novos marcos legais. No caso do ConCidades, esses esforços desembocaram nos levantamentos e sistematizações das atas de reuniões e das suas resoluções, que o presente artigo parcialmente expõe.

Além desta introdução, o trabalho desenvolve-se em três seções. Na primeira, parte-se de uma discussão de caráter contextual que remete ao campo das políticas urbanas, desde alguns antecedentes até a criação do ConCidades. A segunda seção expõe as principais referências teóricas do trabalho, em torno das instituições participativas e de seus elementos de variação, com destaque para o desenho institucional. Abordam-se os traços gerais de variação dos desenhos institucionais participativos, tendo em vista as características gerais dos conselhos, desembocandose no arcabouço analítico estruturado em três eixos: participantes; formas de tomada de decisão e vinculação das decisões às políticas. Na terceira seção, analisam-se as características gerais do desenho institucional do ConCidades, indicando seus potenciais e limites, ao lado de dados relativos a seu funcionamento no período 2004-2010 e a seus impactos nas políticas urbanas. Finalmente, efetuam-se algumas considerações finais, tendo em vista trazer reflexões mais gerais, mas também contribuir para o aprimoramento dessa instituição participativa.

\section{POLÍTICAS URBANAS: ANTECEDENTES, NOVOS MARCOS E O CONCIDADES}

Na trajetória de urbanização no Brasil, destacamse as enormes desigualdades que se apresentam no acesso à terra urbana, à moradia e aos bens e serviços coletivos, implicando um quadro de disparidades de condições de vida nas cidades. A chamada "crise urbana" marca as últimas décadas do século XX, em que a deterioração de tais condições de vida, especialmente para os mais pobres, evidencia a insuficiência (ou ausência) das políticas urbanas no país (MARICATO \& SANTOS JUNIOR, 2007). Em outros termos, em virtude do relativo descaso do poder público, evidenciam-se déficits de inclusividade nas cidades brasileiras, expressos nas desigualdades socioespaciais e nos processos de exclusão e segregação também impressos no território (BRASIL \& CARNEIRO, 2009).

Esse quadro constitui motes de reivindicações dos movimentos sociais urbanos especialmente no ambiente de redemocratização e na Assembléia Constituinte, que abre uma janela de oportunidades políticas, por meio da possibilidade do encaminhamento de emendas populares, permitindo que forças políticas não hegemônicas viessem a influenciar decisivamente a formulação do texto constitucional. Nesse contexto, novos atores coletivos se articulam, constroem espaços públicos em torno da questão urbana e empreendem ações tendo em vista influir nos rumos das políticas, destacando-se a atuação do Movimento Nacional de Reforma Urbana (MNRU), mais tarde configurado como Fórum Nacional de Reforma Urbana (FNRU), que vem a integrar o ConCidades ${ }^{2}$. Articulando diversos atores da sociedade civil, entre movimentos sociais, acadêmicos, associações profissionais e ONGs, a partir de sua plataforma de reforma urbana - consolidada em premissas do direito à cidade e à cidadania, da função social da propriedade e da gestão democrática das cidades - o referido movimento apresentou uma emenda popular que resultou no capítulo constitucional de política urbana. Esse capítulo incorporou parte de seu conteúdo e, adiante, foi mais significativamente absorvido pelo Estatuto da Cidade - lei que regulamenta a política urbana no país ${ }^{3}$.

O trâmite de 13 anos dessa legislação, aprovada apenas em 2001, indica que a questão urbana não integrou a agenda do governo federal na década de 1990. Nessa direção, Abrúcio (2007, p. 62) aponta o campo das políticas urbanas como a maior fragilidade dos governos na referida década. Ou seja, as conquistas constitucionais não implicaram necessariamente, nem prontamente, em mudanças no nível institucional. Nos anos seguintes à promulgação da nova constituição federal, a questão urbana

\footnotetext{
2 Sobre o MNRU/FNRU, ver Brasil (2004; 2011), Santos Junior (2008) e Menicucci e Brasil (2010).

3 Lei n. 10 257/2001. Além de suas diretrizes ancoradas na pauta reformista societária, o Estatuto provê instrumentos aos municípios endereçados ao desenvolvimento urbano, à regularização fundiária e ao combate aos processos especulativos, bem como estende a obrigatoriedade constitucional de elaboração dos planos diretores. Ver Saule Júnior (1997), Ribeiro e Cardoso (2003), Brasil (2004), Santos Júnior, (2008), Brasil e Carneiro (2009) e Maricato (2010).
} 
continuou carente de um aporte institucional federal próprio. A responsabilidade da política de habitação, por exemplo, passou por cinco diferentes ministérios e secretarias entre 1988 e 2002 (MARICATO \& SANTOS JUNIOR, 2007) e intervenções no âmbito da habitação foram pontuais e sem foco.

A partir de 2003, já no contexto do governo Lula, significativas mudanças são tomadas no rumo das políticas urbanas. A Medida Provisória assinada no momento de posse do então novo presidente, em $1^{\circ}$ de janeiro de 2003, cria o MCidades. Tendo como ministro Olívio Dutra (PT), sua equipe inicial era, em parte, composta por profissionais e ativistas ligados ao FNRU. Dessa forma, não apenas respondeu-se ao vazio institucional no âmbito federal para a problemática urbana, como a produção do novo repertório de políticas urbanas e programas constrói-se em sintonia fina com as plataformas societárias (MARICATO \& SANTOS JUNIOR, 2007; BRASIL \& CARNEIRO, 2009; MARICATO, 2010).

De forma mais geral, percebe-se no governo Lula, especialmente em seu primeiro mandato, uma ênfase participacionista nos diversos campos de políticas públicas e de gestão governamental. Assim, são criados 11 novos conselhos e reformulados outros nove, entre os quais o ConCidades, parte integrante da estrutura do MCidades. Ao lado disso, ampliam-se significativamente o número e o escopo temático das conferências nacionais, incluindo-se as conferências das cidades na nova arquitetura participativa (POGREBINSCHI \& SANTOS, 2010; FARIA, 2008; AVRITZER, 2009; BRASIL \& CARNEIRO, 2009).

A criação do ConCidades ocorre a partir de deliberação da I Conferência Nacional das Cidades (CNC), realizada em sua etapa final (nacional) em outubro de 2003, que teve, como desdobramento, o Decreto n. 5 031/2004 (mais tarde alterado pelo Decreto n. 5 790/2006) que o institui ${ }^{4}$. Uma observação relevante é que a deliberação original da CNC previa que o ConCidades teria natureza deliberativa, mas o referido Decreto estabelece que

\footnotetext{
4 Nota-se que, na ocasião da aprovação do Estatuto da Cidade - no contexto da Habitat +5 -, a Medida Provisória n. 2220 cria o Conselho de Desenvolvimento Urbano, ligado à Presidência da República, mas que não chegou a ser regulamentado ou instalado. Destaca-se ainda que o ConCidades e o próprio Ministério das Cidades constavam do programa de governo de Lula desde 1994, então previstos em documento como Ministério da Reforma Urbana e Conselho Nacional de Politica Urbana. Em 1988, o documento de campanha "Projeto Moradia" reafirma essas diretrizes e prevê, ainda, a criação de um sistema nacional de moradia e a realização de conferências (MARICATO, 2006; Grazia e Rodrigues apud BRASIL, 2011, p. 165).
}

tenha caráter deliberativo apenas em relação à regulamentação de seu funcionamento e das conferências e caráter consultivo em relação às suas atribuições, entre as quais de propor diretrizes para a formulação e implementação da política nacional de desenvolvimento urbano, bem como acompanhar e avaliar sua execução de acordo com o Estatuto da Cidade.

Na trajetória do novo ministério e do ConCidades, merece menção a troca de ministros, com a saída de Olívio Dutra (PT) e a entrada de Márcio Fortes, do Partido Progressista (PP). Tal evento ocasionou protestos e questionamentos de atores coletivos do campo reformista integrantes do ConCidades e, mais além, acarretou paulatinamente a saída de quadros do FNRU do MCidades e alguns revezes (BRASIL, 2011).

No período 2003-2010, contudo, destaca-se a realização dos ciclos de conferências nacionais das cidades (em 2003, 2005, 2007 e 2010) que, a partir de 2005, entrelaçam-se com o ConCidades, que mantém seu funcionamento regular e ativo no período. $\mathrm{Na}$ conjunção entre o novo ministério e as instituições participativas criadas, ressalta-se a estruturação de políticas de desenvolvimento urbano nas áreas de habitação de interesse social, de regularização fundiária, de programas urbanos, de saneamento, transporte, mobilidade e a formulação e aprovação de instrumentos legais destinados à sua regulamentação. Os avanços no campo das políticas, que têm sido cunhados no âmbito federal, podem ser atribuídos, em larga medida, às diversas formas de participação social, desde a participação na linha do ativismo e mobilização às formas de participação institucionalizadas, como as conferências nacionais e o ConCidades.

\section{PARTICIPAÇÃO, DESENHOS INSTITUCIO- NAIS E ALCANCES DEMOCRÁTICOS DOS CONSELHOS}

$\mathrm{Na}$ discussão anterior mencionou-se os potenciais que têm sido vislumbrados para as instituições participativas, assim como a heterogeneidade desses arranjos e das práticas que ocorrem nesses espaços, além da variação em seus alcances quanto às possibilidades de aprofundamento democrático e da capacidade de determinar políticas, sobretudo no que diz respeito a gerar modelos alternativos e propiciar a inclusão social.

As diversas abordagens, na literatura nacional, das instituições participativas ${ }^{5}$ e de seus potenciais têm

\footnotetext{
5 Ver, entre outros, Santos (2002), Tatagiba (2002), Brasil (2004; 2011), Gohn (2004), Avritzer e Pereira (2005), Côrtes (2005), Faria (2008), Lüchmann (2008), Avritzer (2009a), Silva (2011) e
} 
apontado fatores distintos de variação nos processos de "participação-deliberativa" 6 e seus resultados, tais como: $(i)$ o perfil da sociedade civil local e a tradição associativista; (ii) a coalizão de sustentação do governo e as respectivas agendas partidárias; (iii) a vontade política e a centralidade conferida à participação pelos governos; (iv) o legado prévio e as aprendizagens institucionais no campo da participação. Apontam, também: (i) a natureza da política; (ii) seu marco legal, inclusive no que tange a recomendação ou exigência de criação de canais participativos e, ainda, (iii) o contexto institucional resultante da articulação entre sociedade e Estado.

O desenho institucional das instituições participativas constitui um elemento ao qual tem se atribuído importância (FUNG \& WRIGHT, 2003; FUNG, 2004; AVRITZER, 2008; LÜCHMANN, 2008; BRASIL et alii, 2010; FARIA \& RIBEIRO, 2011; PIRES, 2011), considerando-se que suas características podem favorecer ou prejudicar a qualidade dos processos participativos e deliberativos, bem como afetar a capacidade decisória e o funcionamento de tais canais. Nesse sentido, mesmo em contextos nos quais se apresenta uma sociedade civil ativa e algum grau de comprometimento político do governo com a agenda participacionista, o desenho institucional pode implicar fortes limitações aos potenciais de participaçãodeliberativa, que podem ser reduzidos a um caráter ritualístico ou constrangidos pelas lógicas burocratizantes.

Entre os autores que consideram os desenhos institucionais como um fator relevante, Avritzer (2008, p. 4) argumenta que o desenho, por si só, não teria o potencial de gerar êxito participativo. Porém, ao lado de outros fatores contextuais, reconhece a importância do desenho institucional, conferindo relevo à forma com a qual este se articula com a organização da sociedade civil e à vontade política. $\mathrm{O}$ autor identifica traços centrais dos desenhos das instituições participativas brasileiras, como os desenhos de "partilha de poder" entre Estado e sociedade, no caso dos conselhos; os desenhos "de baixo para cima", no caso dos orçamentos participativos (podendo-se estender esse caráter às conferências), que teriam um maior potencial democrático, desde as possibilidades mais inclusivas decorrentes do acesso livre e aberto dos participantes.

a coletânea organizada por Pires (2011).

6 Noção empregada por Cohen e Fung (2004) referida às práticas que conjugam formas de participação e de deliberação, esta última remetendo à dimensão discursiva e comunicativa na linha habermasiana.
Por sua vez, Fung (2004; 2006) tem atribuído importância central às variações do desenho institucional como uma chave para as possibilidades de aprofundamento democrático associadas aos canais de participação institucionalizada. Fung (2006) aponta três dimensões fundamentais de variação do desenho: (i) quem participa; (ii) como se comunicam e se tomam as decisões e (iii) como as decisões vinculamse às políticas.

Partindo desses registros para o desenvolvimento do artigo, o primeiro elemento a ser analisado referese aos participantes, destacando-se que, no caso dos conselhos, o acesso não é livre, mas a limitação em relação ao número e perfil dos participantes pode ser atenuada se o desenho possibilitar reuniões abertas com direito à voz e prever, complementarmente, a realização de reuniões e audiências ou, ainda, como no caso do ConCidades, acoplar-se à realização periódica de conferências que permitam capilarizar a participação.

A participação nos conselhos é essencialmente conjugada com mecanismos de representação. Nesse sentido, uma chave consiste na própria composição do conselho, desde o balanceamento entre Estado e sociedade aos diferentes segmentos representados. No primeiro caso, Lüchmann (2008) indica que a paridade não necessariamente garante representação política, na medida em que, de um lado, têm-se os representantes da sociedade civil, que partem de uma condição de heterogeneidade e, de outro, os representantes do governo, que, em tese, partem de uma situação de unidade. No segundo caso, cabe considerar, como sinalizam Avritzer e Pereira (2005), se a definição dos segmentos incorpora os eixos de conflito que, no caso da política urbana, mostram-se expressivos em face dos fortes interesses imobiliários nela inscritos. Outra chave relativa aos participantes refere-se à própria escolha dos representantes, ou seja, como se define e constrói a representação, que pode revestir-se de um caráter mais democrático se constituída por meio de eleições ou de processos deliberativos, por exemplo, atrelados às dinâmicas das conferências.

O segundo elemento consiste nas práticas de participação e de deliberação na formação das decisões e tomadas de decisão. Para além de sua dimensão de ativismo político, a noção de participação, na linha de Pateman (1970), evoca as possibilidades de intervenção ou de influência nas tomadas de decisão e, como indica Faria (2008), tem sido associada a mecanismos de agregação de preferências, como o voto. Por sua vez, a noção de deliberação vincula-se, a partir dos alicerces habermasianos, aos fundamentos intersubjetivos e racionais de comunicação, que se voltam para a construção de consensos. Contudo, os desafios aos potenciais de inclusão política e as críticas às exigências 
normativas da deliberação nesses moldes, que se apresentam em autores como Young (2001), têm levado ao alargamento da noção, que passa a acomodar outras formas de expressão, como a perspectiva de diálogo tendo em vista as convergências e acordos possíveis (FARIA, 2008). Tal distensão também implica o reconhecimento de conflitos irreconciliáveis e a concessão a elementos não deliberativos, como o recurso ao voto e à negociação entre antagonistas (BRASIL, 2011). Nessa linha, cabe examinar as práticas de participação e deliberação envolvidas que se apresentam nos processos de participação-deliberativa.

$\mathrm{O}$ terceiro eixo refere-se às formas de vinculação das decisões às políticas. Nesse sentido, uma primeira chave é o poder efetivo do canal participativo, se formalmente restrito à influência nas decisões ou à intervenção nos processos decisórios com caráter vinculante, cabendo ainda examinar os alcances e objetos da participação desde as atribuições da instituição participativa sob foco. Para além dessas definições, sob tais aspectos cabe verificar os efeitos ou desdobramentos dos processos de participação no âmbito das políticas.
IV. ANÁLISE DO CONCIDADES: DESENHO INSTITUCIONAL PARTICIPATIVO, FUNCIONAMENTO EALCANCES DEMOCRÁTICOS

\section{IV.1. Participantes: composição e novas formas de protagonismo societário}

A I Conferência Nacional das Cidades determinou a composição do ConCidades, como indicado na Tabela 1, com 71 representantes de diversos segmentos sociais. Tal composição não é propriamente paritária, na medida em que o governo federal dispõe de 14 representações. No entanto, considerando-se as representações do poder público nos diversos níveis de governo, o arranjo aproxima-se da paridade. Destaca-se, na composição por segmento, o número de representações destinadas aos movimentos sociais, o que denota o caráter de inclusividade política do conselho. A composição inicial veio a ser alterada posteriormente, por força do Decreto n. 5 790/2006, com um aumento no número total de representantes, passando de 71 para 86 conselheiros. O segmento de movimentos populares teve um acréscimo de quatro representantes, o que contribui para consolidá-lo como o de maior expressão. Ressalta-se a vinculação de seus representantes ao FNRU, favorecendo alinhamentos e um consequente peso a essas representações.

TABELA 1 - COMPOSIÇÃO DO CONCIDADES DE ACORDO COM OS DECRETOS N. 5 031/2004 E 5 790/2006

\begin{tabular}{|l|c|c|}
\hline Segmento & $\begin{array}{c}\text { Número de } \\
\text { representantes de } \\
\text { acordo com o Decreto } \\
\text { n. 5 031/2004 }\end{array}$ & $\begin{array}{c}\text { Número de } \\
\text { representantes de } \\
\text { acordo com o Decreto } \\
\text { n. 5 790/2006 }\end{array}$ \\
\hline $\begin{array}{l}\text { Poder público federal } \\
\text { Poder público estadual e do Distrito Federal ou de } \\
\text { entidades da sociedade civil organizada da área estadual } 7\end{array}$ & 14 \\
$\begin{array}{l}\text { Poder público municipal ou de entidades da sociedade civil } \\
\text { organizada da área municipal }\end{array}$ & 6 & 16 \\
Entidades da área dos movimentos populares & 10 & 12 \\
Entidades da área empresarial & 19 & 23 \\
Entidades da área de trabalhadores & 7 & 8 \\
Entidades da área profissional, acadêmica e de pesquisa & 7 & 6 \\
ONGs & 5 & 4 \\
Total & 3 & 86 \\
\hline
\end{tabular}

FONTE: Os autores.

Ou seja, o relativo sobrepeso do segmento de movimentos populares mostra-se ainda mais expressivo

\footnotetext{
7 O decreto n. 5 790/2006 estabeleceu que deve ser obedecido um critério de rodízio entre os estados.
}

quando se consideram suas articulações com representantes de entidades representativas de trabalhadores, das áreas profissional, acadêmica e de pesquisa, e com algumas ONGs que têm tido assento do ConCidades e que integram o FNRU. Nesse sentido, destaca-se a proeminência, nos dois mandatos do 
governo Lula, de representantes de tais entidades que integram o referido Fórum, totalizando 26 representações no primeiro mandato (SANTOS JÚNIOR, 2007; BRASIL, 2011).

Destaca-se, ainda, a partir de Brasil (2011), que os assentos destinados aos movimentos sociais têm sido ocupados por articulações ou redes nacionais de movimentos, caracterizados pela capilaridade e por práticas deliberativas recorrentes desde suas bases, com assembleias e encontros periódicos, como ocorre também com o próprio Fórum, aglutinando outros segmentos já mencionados.

A partir dessa articulação societária e da prática adotada pelas entidades que integram o FNRU de realização de reuniões dos seus representantes antecedendo as reuniões do ConCidades, destacam-se alinhamentos societários que se mostram decisivos nas tomadas de decisão do referido Conselho (idem), não ocorrendo, assim, o problema mencionado por Lühmann (2008). Ou seja, apesar de eixos de conflitos dos representantes dos segmentos da sociedade - tendo em vista os interesses representativos do setor imobiliário -, os segmentos ligados ao campo da reforma urbana têm um peso maior.

A existência dessa articulação societária e seu alinhamento prévio transcende, portanto, os enquadramentos do desenho institucional do ConCidades. Vale dizer que, com uma ampla participação e representação de segmentos vinculados ao campo de reforma urbana com uma longa trajetória de mobilização, o ConCidades possibilita o trânsito de suas pautas e propostas e sua relativa absorção política.

Entretanto, tais instituições participativas não configuram simples rebatimentos ou traduções da agenda reformista. Constituindo instâncias de deliberação em sua dupla dimensão - decisional e discursiva - canalizam e processam conflitos entre projetos, valores e interesses distintos e antagônicos dos diversos segmentos por meio de seus representantes. Nesses espaços, apresentam-se eixos de conflitos a partir dos interesses privados, assim como feixes de tensionamentos dos representantes do governo e da sociedade civil, que não constituem campos monolíticos (BRASIL, 2011), sincrônica ou diacronicamente. Por outro lado, em relação aos participantes, um problema evidente desde as primeiras reuniões refere-se à baixa participação de alguns segmentos do governo federal, notadamente das áreas fazendária e de planejamento, fato que, em alguma medida, fragiliza o conselho.

Ainda em relação aos participantes e às formas de representação, definiu-se, em ambos os decretos, que a escolha das representações por segmento dar-se-ia por meio de assembléias da sociedade. $\mathrm{O}$ segundo decreto estabeleceu que tais eleições dar-se-iam no espaço das conferências nacionais das cidades, formalizando um rito que na prática já ocorria. Os mandatos dos membros do referido Conselho eram de dois anos e passaram a ser de três, a partir do Decreto n. 5 790/2006, conectando-se à periodicidade das conferências, que também se alterou. Ou seja, no que se refere aos participantes e suas representações, a arquitetura do ConCidades apresenta traços que favorecem a inclusão política.

\section{IV.2. Os processos deliberativos e participativos}

As reuniões ordinárias do ConCidades ocorrem trimestralmente com pelo menos dois dias de duração. $\mathrm{O}$ desenho institucional do referido Conselho inclui comitês temáticos, que se reúnem para discussão de suas pautas específicas, depois encaminhadas em plenária. Os comitês constituem, assim, um espaço de deliberação que nem sempre logra alcançar consenso ou convergência em todos os pontos das pautas, como ocorreu mais de uma vez nas discussões de projetos de lei que passaram pelo ConCidades, mas que não obtiveram consenso ou acordo em todo seu conteúdo.

Nas práticas do ConCidades, assim, conjugam-se formas de representação e de deliberação - neste último caso, no sentido ampliado e recente do termo, como forma de diálogo-, que se voltam para as convergências possíveis e acomodam também o emprego de recursos não deliberativos, como negociações e voto, nos casos de conflitos irreconciliáveis, mantendo-se a justificação como um traço essencial desses processos (idem). As deliberações e os alinhamentos prévios, já mencionados, dos atores no campo da reforma urbana mostramse importantes nos processos decisórios do Conselho.

Na Tabela 2, indica-se a voz e o caráter das manifestações dos conselheiros durante as reuniões do ConCidades, considerando-se as manifestações de contestação ou reclamação e as de cunho propositivo. Ou seja, a perspectiva é de se considerarem os processos participativo-deliberativos de forma ampla, incluindo a dimensão conflitual envolvida. Para sua elaboração, selecionaram-se 12 atas de, respectivamente, 12 reuniões ordinárias do Conselho, sendo que, de modo a proporcionar um recorte comparativo, seis delas correspondem ao período da gestão do ministro Olívio Dutra (atas $1^{\mathrm{a}}$ a $6^{\mathrm{a}}$ ), e seis remetem ao período da gestão do ministro Marcio Fortes (atas $7^{\mathrm{a}}$ a $23^{\mathrm{a}}$ ), estas aleatoriamente escolhidas. Assim, foram registradas as falas que expressavam contestações ou reclamações e proposições, por segmento representado no conselho. 
TABELA2 - NÚMERO DE FALAS QUE EXPRESSARAM CONTESTAÇÃO OU RECLAMAÇÃO E PROPOSIÇÃO, POR SEGMENTO E REUNIÃO DO CONCIDADES

\begin{tabular}{|c|c|c|c|c|c|c|c|c|c|c|c|c|}
\hline \multirow{2}{*}{ Setor } & \multicolumn{12}{|c|}{$\begin{array}{l}\text { Número de falas contrapositivas e propositivas ordenado por número da } \\
\text { Reunião Ordinária do ConCidades }\end{array}$} \\
\hline & $1^{\mathrm{a}}$ & $2^{a}$ & $3^{a}$ & $4^{a}$ & $5^{a}$ & $6^{a}$ & $7^{a}$ & $11^{\mathrm{a}}$ & $13^{a}$ & $19^{a}$ & $21^{a}$ & $23^{a}$ \\
\hline Poder público federal & 2 & 0 & 3 & 1 & 1 & 1 & 0 & 0 & 0 & 2 & 2 & 0 \\
\hline Poder público estadual & 0 & 3 & 7 & 2 & 1 & 2 & 4 & 0 & 0 & 1 & 1 & 2 \\
\hline Poder público municipal & 0 & 15 & 0 & 6 & 1 & 4 & 11 & 0 & 0 & 1 & 2 & 0 \\
\hline Entidades do movimento popular & 1 & 16 & 18 & 17 & 14 & 3 & 25 & 4 & 0 & 11 & 5 & 5 \\
\hline Entidades empresariais & 0 & 8 & 7 & 3 & 0 & 0 & 5 & 0 & 0 & 0 & 2 & 0 \\
\hline Entidades de trabalhadores & 1 & 0 & 8 & 7 & 3 & 2 & 0 & 1 & 3 & 1 & 4 & 5 \\
\hline $\begin{array}{l}\text { Entidades profissionais, } \\
\text { acadêmicas e de pesquisa }\end{array}$ & 0 & 5 & 6 & 4 & 0 & 1 & 12 & 0 & 0 & 4 & 5 & 1 \\
\hline ONGs & 3 & 1 & 4 & 7 & 0 & 2 & 14 & 0 & 0 & 8 & 5 & 6 \\
\hline
\end{tabular}

FONTE: Os autores, a partir das atas das Reuniões Ordinárias do ConCidades.

Para além das indicações expressas na Tabela 2, a pesquisa mostrou que, a partir da $9^{\text {a }}$ Reunião, ocorrida no início de 2006, houve uma mudança na forma de se redigir as atas, que deve ser registrada. Todas as atas a partir dessa reunião e, em especial, entre ela e a $17^{\mathrm{a}}$ Reunião, foram redigidas de forma mais sumária, muitas vezes não apresentando as diversas falas que ocorreram no debate. Nessa forma de redação preferiuse escrever, por exemplo, "foi discutido" ou "propôsse", em vez de explicitar cada fala e seu autor. Não obstante tais problemas decorrentes de uma análise tecida a partir de atas elaboradas por terceiros, percebese que, após a efervescente $7^{\mathrm{a}}$ Reunião - a primeira da gestão do Ministro Márcio Fortes -, em que se discutiu a regulamentação da lei sobre a política nacional de habitação de interesse social, há uma nítida tendência de declínio do registro das falas contestatórias e propositivas, englobando todos os segmentos, com exceção quiçá do segmento de ONGs.

Contudo, mesmo diante de tal inflexão, a partir do conteúdo das atas indica-se a vitalidade dessa instituição participativa, evidente não apenas em virtude das proposições, mas também do caráter de resistência. Nessa linha, na convergência entre contestação e proposição têm-se reivindicações recorrentes e vigorosas de mudança da natureza do Conselho para deliberativo, ampliando seu poder de influenciar as políticas urbanas.

\section{IV.3. Como as decisões se vinculam às políticas}

Como já mencionado, o Decreto de criação do ConCidades atribuiu-lhe caráter consultivo e deliberativo. No entanto, tal caráter deliberativo restringe-se, na verdade, às deliberações acerca de seu regimento interno, ou seja, às decisões sobre sua autorregulamentação. Assim, pode-se pensar que o desenho de natureza predominantemente consultiva limita sua capacidade de engendrar mudanças institucionais. Como afirma Brasil (2011), tal traço limitante, além de muito problematizado em documentos do FNRU, é também objeto de debate e propostas nas Conferências e no próprio ConCidades desde sua primeira reunião, sendo que uma das resoluções do Conselho faz proposições de mudanças que lhe assegurem caráter deliberativo. Entretanto, até o momento essa pretensão não foi concretizada.

Não obstante o caráter marcadamente consultivo, é importante destacar que as 34 resoluções do ConCidades no período da gestão do Ministro Olívio Dutra (entre 2003 e julho de 2005), indicadas na Tabela 3 , são objeto de encaminhamento e processamento, resultando, na maior parte dos casos, na implementação das medidas propostas. Além disso, grande parte dessas medidas envolve recomendações a outros órgãos federais, assim como ao Congresso Nacional, ao lado de orientações aos municípios (BRASIL, 2011). Ou seja, para além dos limites do desenho institucional, a partir da vontade ou comprometimento político, o Conselho não apenas mostrou seu potencial de significativa influência nos processos decisórios no âmbito do MCidades e alguma influência em outros órgãos governamentais para os quais endereçou resoluções, como de fato incidiu nas políticas urbanas desde a sua formulação.

Entretanto, o próprio Conselho não se mostrou imune às mudanças políticas no MCidades. Em uma manobra de ampliação da base parlamentar de apoio do governo, o referido Ministério, como já mencionado, teve sua direção mudada, com o Ministro Márcio Fortes, do PP. Para além do esvaziamento 
progressivo da equipe vinculada ao campo da reforma urbana do MCidades, que acarreta, adiante, mudanças nas suas representações no ConCidades, têm-se algumas implicações relativas ao próprio funcionamento da instituição participativa ${ }^{8}$. Nesse sentido, destaca-se a manifestação de conselheiros em reuniões que ocorreram em 2009, reportando o esvaziamento relativo do referido conselho, com a ausência de representantes do governo federal e do próprio ministro e, também, a própria dinâmica com informes excessivos em detrimento de debates substantivos e políticos.

Outras mudanças evidentes, de modo nítido, consistem no ritmo mais lento de processamento das resoluções elaboradas pelo ConCidades em relação à gestão anterior do MCidades.

TABELA 3 - TIPO E NÚMERO DE RESOLUÇÕES DO CONCIDADES (2004-2010)

\begin{tabular}{|l|c|c|c|c|c|c|c|c|}
\hline \multirow{2}{*}{ Tipo de resolução } & \multicolumn{7}{|c|}{ Número de resoluções por ano } \\
\cline { 2 - 9 } & $\mathbf{2 0 0 4}$ & $\mathbf{2 0 0 5}$ & $\mathbf{2 0 0 6}$ & $\mathbf{2 0 0 7}$ & $\mathbf{2 0 0 8}$ & $\mathbf{2 0 0 9}$ & $\mathbf{2 0 1 0}$ & Total \\
\hline Resoluções normativas & 1 & 1 & 3 & 1 & 3 & 1 & 2 & 11 \\
Resoluções recomendadas & 15 & 11 & 24 & 10 & 15 & 13 & 9 & 75 \\
Resoluções administrativas & 7 & 3 & 3 & 3 & 7 & 2 & 0 & 15 \\
Total & 23 & 15 & 30 & 14 & 25 & 16 & 11 & 134 \\
\hline
\end{tabular}

FONTE: Os autores, adaptado de Brasil (2011) e a partir das resoluções do ConCidades.

Ao examinar-se o funcionamento do ConCidades e o potencial deliberativo de suas decisões, é interessante observar o número e a natureza de suas resoluções. A Tabela 3 toma como parâmetro o número de resoluções publicadas por ano entre sua instalação em 2004 e o final de 2010. Esclarece-se que a identificação do "tipo de resolução" decorre de uma mudança imediata a partir da entrada do Ministro Marcio Fortes. Na gestão anterior do MCidades, de 2004 a meados de 2005, foram produzidas resoluções tanto em relação às atribuições consultivas quanto deliberativas, indiferenciadas quanto à sua denominação. Com a mudança na direção do MCidades, a numeração das resoluções foi reiniciada, distinguindo-se entre resoluções normativas ("resoluções reservadas à regulamentação e normatização dos atos do ConCidades"), administrativas ("resoluções concernentes aos atos administrativos necessários à gestão do ConCidades" e recomendadas (referentes às atribuições consultivas; "resoluções relativas aos atos de outras unidades administrativas das esferas do Poder Público e entidades da sociedade civil"). Assim, para efeitos comparativos, as resoluções da gestão de Olívio Dutra, ou seja, as que não tinham diferenciação tipológica, foram enquadradas em tal diferenciação.

\footnotetext{
8 Em algumas reuniões têm-se reclamações pontuais quanto à dinâmica do Conselho. Ver Brasil (2011) para a análise desses rebatimentos no ConCidades.

9 Destas, dez foram produzidas até julho de 2005, ou seja, durante a gestão de Olívio Dutra. No restante do ano, já na gestão de Márcio Fortes, foram produzidas apenas cinco.
}

Ressalta-se que as resoluções recomendadas são as que de fato vinculam-se diretamente ao conteúdo das políticas urbanas, embora as resoluções normativas também sejam importantes, na medida em que se voltam para a regulamentação do ConCidades e da CNC, ou seja, dos próprios processos participativos que afetam a formulação das políticas.

Ainda que 2006 constitua o ano de maior atividade no que se refere à publicação de resoluções, percebese, em geral, uma tendência ao decréscimo do número de resoluções, especialmente a partir de 2007. Tal fato pode indicar certo estrangulamento do poder do Conselho. A ausência de discussão prévia no âmbito do ConCidades acerca de programas estratégicos para o governo, como o Programa de Aceleração do Crescimento (PAC), lançado em 2007, e o Programa Minha Casa Minha Vida (PMCMV), lançado em 2009, sinaliza nessa direção. Embora tenha fortalecido expressivamente o MCidades em relação aos recursos disponibilizados, tanto as diretrizes como a própria concepção do PAC foram elaboradas à margem do ConCidades e das políticas então estruturadas. Já o PMCMV "atropelou" as diretrizes do Plano Nacional de Habitação, que havia sido discutido e aprovado anteriormente no âmbito do ConCidades. Entretanto, tais programas foram objeto de debates intensos no Conselho, quando de seus respectivos lançamentos, em um processo que resultou em algumas alterações e ajustes relevantes na concepção e desenho dos mesmos (BRASIL, 2011). Como indicado, parte significativa da equipe, composta por profissionais e ativistas do campo da reforma urbana, deixou o MCidades no primeiro momento de mudança de Ministros; os 
atravessamentos mencionados implicaram a saída de outros quadros reformistas em 2007.

Em relação à publicação de resoluções, ao analisarse a listagem numerada de resoluções publicadas disponíveis no site do ConCidades, observa-se ainda que algumas delas não foram publicadas, indicando um estrangulamento em seu processamento no âmbito do MCidades, a partir da gestão do Ministro Márcio Fortes. É o que mostram os dados apresentados na Tabela 4.

TABELA 4 - TIPO E NÚMERO DE RESOLUÇÕES NÃO PUBLICADAS

\begin{tabular}{|l|c|}
\hline Tipo de Resolução & $\begin{array}{c}\text { Número de } \\
\text { resoluções } \\
\text { não publicadas }\end{array}$ \\
\hline $\begin{array}{l}\text { Resoluções em geral } \\
\text { (gestão Olívio Dutra) }^{10}\end{array}$ & 1 \\
Resoluções Normativas & 1 \\
Resoluções Recomendadas & 23 \\
Resoluções Administrativas & 5 \\
Total & 29 \\
\hline
\end{tabular}

FONTE: Os autores, a partir das resoluções do ConCidades.

Além da contagem do número de resoluções do ConCidades, cabe referenciar seu conteúdo geral. No caso das resoluções normativas, como mencionado, estas se voltaram, em sua maioria, para o regimento interno do ConCidades e das CNCs. No caso das resoluções recomendadas, destaca-se sua profusão, abrangência temática e de finalidade.

Parte significativa das recomendações do ConCidades endereça-se ao poder Executivo e o Legislativo federais; outra parte ao próprio Ministério e às políticas de desenvolvimento urbano. Em relação aos temas das resoluções, sobressaem-se questões de natureza orçamentária ou financeira e assuntos relativos a fundos e alocação de recursos e programas governamentais, especialmente PAC, PMCMV e Crédito Solidário. O rol dos temas tratados inclui também recomendações relativas ao Fundo Nacional de Habitação de Interesse Social (FNHIS); questões relativas aos conflitos fundiários urbanos e à regularização fundiária; e posicionamentos em relação a projetos de lei em trâmite no Legislativo, como a Proposta de Emenda Constitucional que vincula

10 Como já comentado, durante a gestão do referido ministro, não se havia diferenciação quanto ao tipo de resolução. recursos orçamentários à moradia - a PEC 85/2008 , de autoria parlamentar, com a participação do FNRU.

Além dessas questões, Brasil (2011) destaca também resoluções que aprovam e encaminham projetos gestados no MCidades e ConCidades que constituem marcos regulatórios ou que fazem recomendações ao governo quanto à elaboração de projetos de lei específicos. São resoluções aderentes à pauta da reforma urbana e têm sido processadas, podendo-se identificar avanços muito significativos no âmbito legal e normativo, sobretudo na estruturação dos marcos das políticas setoriais, reenquadrando, assim, as políticas urbanas do país.

Cabe registrar que a criação do Sistema Nacional da Habitação de Interesse Social, por meio da Lei n. 1 124/2005, e a regulamentação do já citado FNHIS, foram discutidas e impulsionadas pelo ConCidades. $\mathrm{O}$ Fundo não apenas era uma demanda antiga dos movimentos sociais, como foi objeto de projeto de iniciativa popular dos movimentos sociais no campo da reforma urbana no início dos anos 1990, que deu origem à referida legislação aprovada em 2005. Outros importantes avanços legais foram produzidos a partir do ConCidades, que gestou, discutiu ou impulsionou projetos de lei de regulamentação de políticas urbanas. Incluem-se, aqui, a legislação de consórcios e de saneamento básico, ambas aprovadas ${ }^{11}$, e o projeto de lei de transporte e mobilidade ${ }^{12}$. Além disso, planos setoriais também foram gestados e/ou discutidos no ConCidades, tornando-se objeto de resoluções, como o Plano Nacional de Habitação e o Plano Nacional de Saneamento Básico. Ou seja, no período examinado, o ConCidades indiscutivelmente desempenhou um papel de protagonismo na estruturação das políticas urbanas brasileiras, desde seus marcos regulatórios a planos setoriais de intervenção.

Também parcela expressiva das resoluções recomendadas foi composta de orientações e diretrizes para municípios e estados, em especial no que se refere ao planejamento municipal e à criação de conselhos. Percebe-se, aqui, o potencial de abrangência do impacto que o ConCidades pode ter nas políticas urbanas dos níveis subnacionais de governo. Diversas resoluções voltam-se para os planos diretores participativos e planos setoriais, ou para orientações de integração entre tais planos. Em relação aos conselhos, há resoluções que recomendam a criação

11 As legislações de consórcios e de saneamento básico estão compreendidas, respectivamente, na Lei n. 11795 , de 8 de outubro de 2008, e na Lei n. 11 445, de 5 de janeiro de 2007.

12 Projeto de Lei n. 1 687/2007. 
de conselhos das cidades e que recomendam, ao MCidades, a priorização, em programas sob sua responsabilidade, dos municípios que dispõem de conselhos, incentivando, assim, sua criação. Mais uma vez, são resoluções sintonizadas com a agenda societária de reforma urbana (idem).

O tecido organizativo da sociedade civil no campo das políticas urbanas e a inserção de representantes no ConCidades, ao lado das Conferências, que têm um papel de proposição de diretrizes mas também de acompanhamento das políticas, favorecem o controle público dessa instituição participativa.

\section{CONCLUSÕES}

Ao se considerar as políticas públicas no país e seus avanços nas últimas décadas, é inevitável notar a importância da participação social, desde a dimensão de constituição de identidades coletivas, organizativa e mobilizatória que, no caso das políticas, resultou no capítulo constitucional de política urbana, no Estatuto da Cidade, na legislação de iniciativa popular do FNHIS, entre outros avanços. Ao lado disso, também fica evidente que os processos de participação e de deliberação nas instituições participativas têm engendrado avanços nas políticas públicas e, no caso das políticas urbanas, no sentido de delinear formas alternativas de intervenção voltadas para a inclusividade socioespacial, para o direito à cidade e o cumprimento da função social da propriedade e da cidade e para o planejamento e gestão urbana democrática.

O ConCidades, em foco neste artigo, constituiu um dos marcos centrais para as políticas urbanas no país, que não apenas são incorporadas na agenda federal na década anterior, como o são sob novas orientações, premissas e moldes, em sintonia com as plataformas da sociedade civil organizada e ativista. A criação do MCidades constituiu o pilar inicial dessas mudanças, ao lado da nova arquitetura participativa composta pelas CNCs e pelo ConCidades que, em seu desenho e finalidade, mostram-se complementares, propiciando a inclusão política de segmentos antes excluídos de processos decisórios.

A análise do desenho institucional que circunscreve as experiências de participação-deliberativa mostra-se relevante, na medida em que sua abordagem pode contribuir para a compreensão das práticas participativas e para as possibilidades de seu aprimoramento e de distensão de limites, notadamente no caso em questão, em virtude da experiência ainda recente. O exame do desenho do ConCidades, a partir das categorias analíticas selecionadas, indicou seu potencial democrático e de engendrar avanços nas políticas urbanas, bem como algumas limitações, notadamente seu caráter consultivo, que tem sido objeto de questionamentos societários e propostas de alteração. Nesse sentido, indicou-se também que, a despeito desse limite, o comprometimento político com uma agenda participacionista e de inclusão social, em especial na gestão do Ministro Olívio Dutra, permitiu ultrapassar o problema.

$\mathrm{O}$ trabalho indicou ainda algumas mudanças em virtude de rearranjos políticos e da mudança de gestão, sobretudo em relação ao timing de processamento das decisões e resoluções do ConCidades. A despeito das contradições e dificuldades delas derivadas, o ConCidades continuou em funcionamento ativo e concretizando potenciais de intervenção no desenho e curso das políticas, desde seus marcos regulatórios aos planos, engendrando e impulsionando avanços importantes.

A partir do exame do desenho institucional indicouse, ainda, que os processos de participação-deliberativa no interior da sociedade civil podem afetar de forma decisiva as práticas no interior das instituições participativas e seus resultados. A atuação do FNRU, a partir da articulação e do alinhamento prévio dos atores que o integram e têm representação no ConCidades, vem favorecendo decisões na linha da agenda de reforma urbana.

Nesse sentido, a despeito de terem sido destacados os potenciais das instituições participativas e de seu experimentalismo democrático, que o próprio ConCidades revela, os problemas e limitações dessas novas formas de participação sinalizam para a complexidade dos processos de construção e de aprofundamento democrático. Indicou-se, assim, o papel importante dos atores da sociedade civil, não apenas a partir de sua inclusão política em tais instituições, mas também em uma atuação na linha mobilizatória e ativista.

Por fim, o quadro socioespacial das cidades brasileiras e os déficits históricos de inclusividade socioespacial indicam ainda um longo caminho para a concretização de propostas de reforma urbana e para a construção de cidades mais justas, includentes, sustentáveis e democráticas, implicando desafios vultuosos para o governo, sociedade civil e para suas interseções nas instituições participativas. 
Flávia de Paula Duque Brasil (flavia.brasil@fjp.mg.gov.br) é Doutora em Sociologia pela Universidade Federal de Minas Grais (UFMG) e Professora na Fundação João Pinheiro (FJP).

Ricardo Carneiro (ricardo.carneiro@fjp.mg.gov.br) é Doutor em Sociologia e Política pela Universidade Federal de Minas Gerais (UFMG) e Professor na Fundação João Pinheiro (FJP).

Thiago Pinto Barbosa (thbarbosa@gmail.com) é Graduado em Ciências Sociais pela Universidade Federal de Minas Gerais (UFMG) e Mestrando em Relações Internacionais pela Universidade Livre de Berlim, Universidade Humboldt de Berlim e Universidade Potsdam.

Mariana Eugenio Almeida (mariana.almeida88@gmail.com) é Mestre em Administração Pública pela Fundação João Pinheiro (FJP) e analista do Observatório do Trabalho na Secretaria de Estado de Trabalho e Emprego de Minas Gerais.

\section{REFERÊNCIAS BIBLIOGRÁFICAS}

ABRUCIO, F. L. 2007. Trajetória recente da gestão pública brasileira: um balanço crítico e a renovação da agenda de reformas. Revista Brasileira de Administração Pública, Rio de Janeiro, v. 41, número especial, p. 67-86, jun. Disponível em: http:// www.scielo.br/pdf/rap/v41nspe/a05v41sp.pdf. Acesso em: 26.ago.2013.

AVRITZER, L. 2008. Instituições participativas e desenho institucional: algumas considerações sobre a variação da participação no Brasil democrático. Opinião Pública, Campinas, v. 14, n. 1, p. 43-64, jun.

2009a. Participatory Institutions in Democratic Brazil. Baltimore: John Hopkins University.

(org.). 2009b. Experiências nacionais de participação social. São Paulo: Cortez.

AVRITZER, L. \& PEREIRA, M. L. D. 2005. Democracia, participação e instituições híbridas. Teoria e Sociedade, Belo Horizonte, número especial, p. 14-39, maio. Disponível em: http://pt.scribd.com/ doc/57941437/Avritzer-leonardo-Pereira-Maria-deLouders-Democracia-participacao-e-instituicoeshibridas. Acesso em: 26.ago.2013.

BRASIL, F. P. D. 2004. Participação cidadã e reconfigurações nas políticas urbanas nos anos 1990. Revista Brasileira de Estudos Urbanos e Regionais, Recife, v. 6, n. 2, p. 35-51, nov.

. 2011. Democracia e participação social: a construção de avanços democratizantes nas políticas urbanas pós-1980. Belo Horizonte. Tese (Doutorado em Sociologia). Universidade Federal de Minas Gerais.

BRASIL, F. P. D. \& CARNEIRO, R. 2009. Os caminhos (e descaminhos) de democratização das políticas urbanas: o que há de novo no Brasil Contemporâneo? Cadernos Gestão Pública e Cidadania, São Paulo, v. 14, n. 55, p. 11-42, jul.-dez.
BRASIL, F. P. D.; CARNEIRO, R.; FRANÇA, B. C. \& ALMEIDA, M. E. 2010. As instâncias locais de participação nas políticas urbanas: uma análise dos desenhos institucionais. Trabalho apresentado no $2^{\circ}$ Seminário de Política e Planejamento, realizado em Curitiba, de 4 a 6 de agosto. Digit.

CHAMBERS, S. A. 2009. Teoria Democrática Deliberativa. In: MARQUES, A. C. S. (org.). A Deliberação pública e suas dimensões sociais, políticas e comunicativas. Belo Horizonte: Autêntica.

COHEN, J. \& FUNG, A. 2004. Radical Democracy. Swiss Journal of Political Science, v. 10, n. 4, p. 23-34, Winter. Disponível em: http:// www.archonfung.com/docs/articles/2004/ Cohen_Fung_Debate_SPSR2004.pdf. Acesso em: 26.ago.2013.

CÔRTES, S. 2005. Fóruns participativos e governança: uma sistematização das contribuições da literatura. In: MELO, M. A.; LUBAMBO, C. \& COELHO, D. B. (orgs.). Desenho institucional e participação política. Experiências no Brasil contemporâneo. Petrópolis: Vozes.

COSTA, S. 1997. Categoria analítica ou passe-partout político-normativo: notas bibliográficas sobre o conceito de sociedade civil. BIB, Rio de Janeiro, n. 43, p. $3-25,1^{\circ}$ semestre.

CUNHA, E. S. M.; ALMEIDA, D. C. R.; FARIA, C. F. \& RIBEIRO, U. C. 2011. Uma estratégia multidimensional de avaliação dos Conselhos de Políticas Públicas. In: PIRES, R. R. C. (org.). Efetividade das instituições participativas no Brasil: estratégias de avaliação. Brasília: IPEA. Disponível em: http:/www.ipea.gov.br/portal/images/stories/ PDFs/livros/livro_dialogosdesenvol07.pdf. Acesso em: 26.ago.2013.

DAGNINO, E. 2002. Sociedade civil e espaços públicos no Brasil. Rio de Janeiro: Paz e Terra. 
DOIMO, A. M. 1995. A vez e a voz do popular: movimentos sociais e participação popular no Brasil pós 70. Rio de Janeiro: Relume Dumará.

DRYZEK, J. 2000. Deliberative Democracy and Beyond: Liberals, critics and contestation. Oxford: Oxford University.

FARIA, C. 2008. O debate sobre participação nas instituições participativas: quais distinções analíticas importam? Trabalho apresentado no $32^{\circ}$ Encontro Anual da Anpocs, realizado em Caxambu (MG), de 27 a 31 de outubro. Digit.

FARIA, C. F. \& RIBEIRO, U. C. 2011. Desenho institucional: variáveis relevantes e seus efeitos sobre o processo participativo. In: PIRES, R. R.C. (org.). Efetividade das instituições participativas no Brasil: estratégias de avaliação. Brasília: IPEA.

FUNG, A. 2004. Receitas para esferas públicas: oito desenhos institucionais e suas conseqüências. In: COELHO, V. S. R. P. \& NOBRE, M. (orgs.). Participação e deliberação: teoria democrática e experiências institucionais no Brasil contemporâneo. São Paulo: Letras.

Varieties of Participation in Complex Governance. Public Administration Review, Washington (DC), v. 66, special issue s1, p. 66-75, Nov. Disponível em: http://www.archonfung.net/ papers/FungVarietiesPAR.pdf. Acesso em: 28.ago.2013.

FUNG, A. \& WRIGHT, E. O. 2003. Deepening Democracy: Institutional innovations in empowered participation governance. London: Verso.

GOHN, M. G. 1995. História dos movimentos e lutas sociais. São Paulo: Loyola.

2004. Os conselhos municipais e a gestão urbana. In: SANTOS JÚNIOR, O.; RIBEIRO, L. \& AZEVEDO, S. (orgs.). Governança democrática e poder local. Rio de Janeiro: Revan.

GUTMAN, A. \& THOMPSON, D. 2007. O que significa a democracia deliberativa. Revista Brasileira de Estudos Constitucionais, Belo Horizonte, ano 1, n. 1, p. 17-78, jan.-mar.

HABERMAS, J. 1997. Direito e democracia: entre factilidade e validade. V. 2. Rio de Janeiro: Tempo Brasileiro.

LÜCHMANN, L. H. H. 2008. O desenho institucional dos conselhos gestores. In: LYRA, R. P. (org.). Participação, democracia e segurança pública. A experiência brasileira. João Pessoa: UFPB.

MARICATO, E. 2010. O estatuto da cidade periféri- ca. In: CARVALHO, C. S. \& ROSSBACH, A. C. (orgs.). O estatuto da cidade comentado. São Paulo: Aliança das Cidades.

MARICATO, E. \& SANTOS JÚNIOR, O. A. 2007. Construindo a política urbana: participação democrática e o direito a cidade. In: RIBEIRO, L. C. Q. \& SANTOS JUNIOR, O. A. (orgs.). As metrópoles e a questão social brasileira. Rio de Janeiro: Fase.

MENICUCCI, T. \& BRASIL, F. P. D. 2010. Construção de agendas e inovações institucionais: análise comparativa da reforma sanitária e reforma urbana. Revista Estudos de Sociologia, Araraquara, v. 15, n. 29, p. 369-396, jun. Disponível em: http:/ /www.eg.fjp.mg.gov.br/index.php/component/ docman/doc_download/277-construcao-de-agendas-e-inovacoes-institucionais. Acesso em: 28.ago.2013.

PATEMAN, C. 1970. Participation and Democratic Theory. Cambridge (UK): Cambridge University.

PIRES, R. R. C. (org.). 2011. Efetividade das instituições participativas no Brasil: estratégias de avaliação. Brasília: IPEA.

POGREBINSCHI, T. \& SANTOS, F. 2010. Entre representação e participação: as conferências nacionais e o experimentalismo democrático brasileiro. Rio de Janeiro: Iuperj.

RIBEIRO, L. C. Q. \& CARDOSO, A. L. 2003. Reforma urbana e gestão democrática: promessas e desafios do Estatuto da Cidade. Rio de Janeiro: Revan.

RODRIGUES, A. M. 2011. Conselho das Cidades uma avaliação. Terra Livre, São Paulo, ano 26, v. 1, n. 34. p. 223-230.

SANTOS, B. S. \& AVRITZER, L. 2002. Para ampliar o cânone democrático. In: SANTOS, B. S. (org.). Democratizar a democracia: os caminhos da democracia participativa. Rio de Janeiro: Civilização Brasileira.

SANTOS, M. R. 2002. Conselhos Municipais: a participação cívica na gestão das políticas públicas. Rio de Janeiro: FASE.

SANTOS JÚNIOR, O. A. 2007. Avaliação do Conselho Nacional das Cidades. Reforma urbana e gestão democrática das cidades: um ano de funcionamento do Conselho das Cidades. Relatório para a FASE.

2008. A Reforma Urbana: desafios para o planejamento como práxis transformadora. In: COSTA, G. M. \& MENDONÇA, J. G. (orgs.). Planeja- 
mento urbano no Brasil: trajetória, avanços e perspectivas. Belo Horizonte: Arte.

SAULE JÚNIOR, N. 1997. Novas perspectivas do direito urbanístico brasileiro: ordenamento constitucional da política urbana. Aplicação e eficácia do Plano Diretor. Porto Alegre: S. Fabris.

SILVA, M. K. 2011. Dos casos aos tipos: notas para apreensão das variações qualitativas das instituições participativas. In: PIRES, R. R. C. (org.). Efetividade das instituições participativas no Brasil: estratégias de avaliação. Brasília: IPEA.

SCHERER-WARREN, I. 1996. Redes de movimentos sociais. $2^{\mathrm{a}}$ ed. São Paulo: Loyola.
TATAGIBA，L. 2002. Conselhos gestores e a burocratização das políticas públicas no Brasil. In: DAGNINO, E. (org.). Sociedade civil e espaços públicos no Brasil. Rio de Janeiro: Paz e Terra.

TEIXEIRA, E. 2000. Sociedade civil e participação cidadã no poder local. Salvador: UFBA.

WARREN, M. 2002. What Can Democratic Participation Mean Today? Political Theory, Thousand Oaks, v. 30, n. 5, p. 677-701, Oct.

YOUNG, I. 2001. Activist Challenges to Deliberative Democracy. Political Theory, Thousand Oaks, v. 29, n. 2, p. 670-690, Oct. Disponível em: https:// www.ucalgary.ca/peacestudies/files/peacestudies/ Young\%20-\%20Day\%202.pdf. Acesso em: 26.ago.2013.

\section{OUTRA FONTES}

CONCIDADES. CONSELHO DAS CIDADES. Resoluções do ConCidades.

Resoluções normativas do ConCidades. Resoluções Recomendas do ConCidades.
. Atas das reuniões ordinárias do ConCidades. . Atas das reuniões extraordinárias 1 e 2 do Conselho das Cidades. 
PARTICIPATION, INSTITUCIONAL DESIGN AND DEMOCRATIC ACHIEVMENTS: AN ANALISYS OF THE COUNCIL OF CITIES.

\section{Flávia de Paula Duque Brasil, Ricardo Carneiro e Thiago Pinto Barbosa}

This paper deals with the social participation at participatory institutions, focusing on the Council of Cities (ConCidades) which was created in 2004 in the federal level in Brazil. The goal of the paper is to analyze the Council's institutional design, its potentials, limits and reach concerning advances in public policy, considering 2004-2010. One posts the question if the different elements of ConCidades' participatory design favor the realization of potentials of inclusion and democratization of public policy, or not. The research was undertaken between 2010 and 2011 and theoretically based on sources in the field of participatory democracy on participatory institutions, its potentials and variation elements. Highlighting that participation is dependent upon contextual factors, its trajectory, civil society's profile, the government's commitment institutional designs, one focuses here on the design of participatory councils. The analytical model based on Fung $(2004,2006)$ is structured in three axes: participants; forms of decision-making; and binding decisions to the policy. The methodology employed qualitative and quantitative resources, conducting documentary collection concerning the Ministry of Cities and urban policies in the period (2004-2010). The minutes of the Conferences of Cities and of the other meetings of ConCidades were systematized and analyzed. The research indicates ConCidades' democratic potential and potential of engendering advances in urban policies and their legal frameworks, with variations along its trajectory. Regarding the design, both composition and form of choice of representatives, among other factors, encourage political inclusiveness and participation. Also some limitations become evident, especially the Council's advisory status in relation to policy decisions, which has been questioned. Beyond the participatory design, institutional changes in the Ministry and processes of participation in civil society have affected the practices within this participatory institution and its outcomes. The action of the collective actors that comprise the National Forum of Urban Reform affected the urban policy through various processes and action repertories. From a more general perspective, the present research lies in the debates about participatory institutions - especially councils - and institutional design as an element that can favor or discourage both the deliberative participation and its effects on policy. Specifically, this paper helps the debate on such issues by focusing on a recent, relatively little discussed and yet to be improved - experience of participation in federal urban policies.

KEYWORDS: democracy; social participation; participatory instutional design; Council of the Cities; urban policys. 